\title{
De Roosevelt, mas também de Getúlio: o Serviço Especial de Saúde Pública
}

\author{
From Roosevelt, but from Getúlio as well: \\ the Serviço Especial de Saúde Pública
}

\author{
Jorge Ferreira \\ Universidade Federal Fluminense - UFF \\ jorge-fer@uol.com.br
}

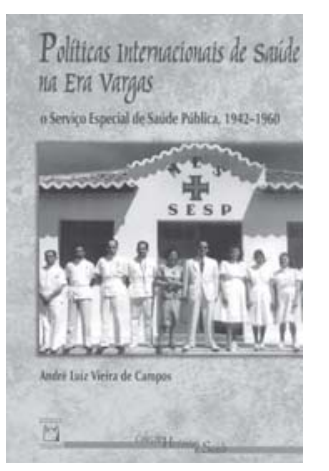

Campos, André Luiz Vieira de.

Políticas internacionais de saúde na era Vargas: o Serviço Especial de Saúde Pública, 19421960. Rio de Janeiro: Ed. Fiocruz, 2006. 318p.
$\mathrm{U}$ ma das conseqüências do envolvimento dos Estados Unidos na Segunda Guerra Mundial foi a reorientação de sua política externa para a América Latina. Nelson Rockefeller, por exemplo, liderou e patrocinou uma série de iniciativas no sentido de aproximar, em termos políticos e culturais, os Estados Unidos dos países latino-americanos. Uma das instituições criadas com essa finalidade foi o Instituto de Assuntos Interamericanos (Iaia). Entre seus programas de cooperação com países da América Latina estavam as políticas de saúde e saneamento.

O Brasil foi considerado parceiro privilegiado na nova política externa norte-americana. Mas, no caso de nosso país, havia um interesse em especial. Prestes a entrarem na Segunda Guerra Mundial, os Estados Unidos necessitavam de bases militares no Nordeste brasileiro. Sua indústria bélica era voraz consumidora de borracha extraída dos seringais amazônicos e dos minerais do vale do Rio Doce, em Minas Gerais. O interesse no Brasil era estratégico, se não vital, para a participação norte-americana na guerra. No entanto, todas essas regiões no território brasileiro eram infestadas por doenças graves como malária, tuberculose e febre tifóide, bem como aquelas provocadas por parasitas intestinais. Doenças sexualmente transmissíveis também preocupavam os norte-americanos.

Para segurança e bem-estar dos milhares de soldados norte-americanos que viriam ao Nordeste, e para aumentar a produtividade de seringueiros e de trabalhadores das minas, era necessário desenvolver campanhas de combate a esses males. Necessárias, também, eram medidas preventivas e terapêuticas como construção de hospitais, clínicas e postos de saúde, bem como redes de esgotos e água tratada. Não se poderia esquecer, igualmente, da educação sanitária e do treinamento de médicos, enfermeiras e agentes sanitários. Com essas preocupações foi criado, em julho de 1942, o Serviço Especial de Saúde Pública (Sesp), com estatuto jurídico especial e autonomia em relação ao Ministério da Educação e Saúde. Resultado de um acordo bilateral entre Brasil e Estados Unidos, o Sesp implementaria, em território brasileiro, as diretrizes do Instituto de Assuntos Interamericanos.

Em razão de suas origens, durante os 48 anos seguintes o Sesp foi visto com desconfiança entre muitos profissionais de saúde no Brasil. Além de sua plena autonomia administrativa e financeira, valorizando 
seus funcionários com salários compatíveis, o órgão ainda defendia estratégias e políticas de saúde pública aplicadas nos Estados Unidos, mantendo vínculos técnicos, institucionais e simbólicos com os padrões norte-americanos. Apontado como instituição estrangeira no país e alienada da realidade nacional, o Sesp foi alvo de várias acusações, entre elas a de antipatriotismo.

Como sustentar tantas versões negativas de uma instituição que se manteve durante quase meio século? E, afinal, qual foi a atuação do Sesp ao longo desses anos e qual a sua contribuição para o avanço da saúde pública no Brasil?

As versões negativas e demeritórias, bem como o conjunto de críticas e desconfianças, somente contribuíram para justificar um estudo sério e aprofundado sobre o Sesp. André Luiz Vieira de Campos, professor do Departamento de História da Universidade Federal Fluminense e da Universidade do Estado do Rio de Janeiro, dedicou-se a enfrentar o tema em seu doutorado na Universidade do Texas. A tese, agora publicada pela Editora da Fiocruz sob o título de Políticas internacionais de saúde na era Vargas, estabelece, de maneira criativa e inteligente, as relações entre a história republicana brasileira, a saúde pública em nosso país e as relações internacionais entre Brasil e Estados Unidos, centrando o foco em uma instituição: o Serviço Especial de Saúde Pública.

O trabalho, sem dúvida, é bem-vindo, sobretudo porque os estudos na área da história da saúde pública no Brasil dedicam-se, em grande parte, à Primeira República, permitindo que o período 1930-1945 esteja ainda muito marcado pelos estudos de temas ditos 'clássicos', a exemplo das ideologias, das lutas operárias e da repressão policial, entre outros. O autor, portanto, inova ao trabalhar com uma abordagem historiográfica recente no Brasil - a história das políticas de saúde em uma temporalidade ainda por explorar.

Concebido durante a Segunda Guerra Mundial para o governo norte-americano, o Sesp seria uma agência temporária, para atuar apenas enquanto durasse o conflito, com a tarefa de desenvolver políticas sanitárias nas regiões produtoras de matérias-primas estratégicas para a indústria bélica, como a Amazônia e o vale do Rio Doce. Sua atuação inicial foi em Belém, cidade em que a malária e a tuberculose eram responsáveis por $60 \%$ das mortes da população adulta. Em Recife e Natal, o Sesp atacou a proliferação de mosquitos transmissores de doenças - como a própria malária. Mais adiante, as preocupações dirigiram-se para a Amazônia e Minas Gerais. Com o tempo, o Sesp desenvolveu políticas de saúde voltadas para as populações do interior do país, estabeleceu uma rede de unidades sanitárias, construiu e administrou escolas de enfermagem, centros de saúde e hospitais, bem como sistemas de águas e esgotos. Além disso, instituiu convênios com estados e municípios, formou mão-de-obra qualificada e implementou a educação sanitária.

Uma das políticas mais atuantes do Sesp foi a da qualificação de profissionais. Bolsas de estudos foram concedidas a médicos, engenheiros sanitários e enfermeiras, entre outros profissionais, que freqüentaram cursos de graduação e pós-graduação em universidades norte-americanas. Outros profissionais realizaram estágios em hospi- 
tais e laboratórios daquele país. O Iaia forneceu livros e revistas especializadas para faculdades de medicina brasileiras. O Sesp também formou técnicos de nível médio, além de guardas sanitários, técnicos de laboratório, auxiliares de saneamento e visitadoras sanitárias. Uma das diretrizes da instituição era a de que a educação sanitária da população mais pobre poderia mudar seus hábitos e, assim, evitar uma série de doenças. A Divisão de Educação Sanitária do Sesp, desse modo, patrocinou programas de educação em saúde, atuando nas escolas pela orientação de alunos e professores.

Outra diretriz da instituição foi a de privilegiar a atuação de postos de saúde que teriam um amplo raio de ação. Os postos coordenavam as visitas que suas enfermeiras faziam às famílias da comunidade; fiscalizavam a rede de água e de esgoto e o recolhimento do lixo; ensinavam práticas de higiene maternal e infantil; patrocinavam cursos de educação sanitária e mantinham formas de controlar as doenças infecciosas; e seus médicos recebiam pessoas da comunidade para a prática clínica.

O Sesp aplicou no Brasil o modelo norte-americano de saúde pública: centros de saúde voltados para a medicina preventiva, com atuação descentralizada e horizontal. Tratava-se de uma prática diferente daquela aplicada no Brasil. O padrão adotado pelo governo Vargas na década de 1930 foi o da atuação centralizada e vertical - compreensível, uma vez que se renegava o liberalismo e o federalismo, marcas do 'antigo regime'. Mas como acontece em casos como esses, a importação de modelos nunca é isenta de adaptações, adequações e negociações com a realidade do país em que se aplica o padrão importado.

Embora o Sesp se inspirasse em políticas de saúde pública vigentes nos Estados Unidos, não há razões para supor que suas estratégias de atuação no Brasil entrassem em contradição com as diretrizes de saúde pública estabelecidas pelo Estado brasileiro nos anos 30, com o Departamento Nacional de Saúde (DNS). Uma das teses que o autor procura demonstrar é exatamente a de que os princípios que norteavam tanto o DNS quanto o Sesp não eram excludentes, embora tivessem características próprias. A proposta do Estado nos anos 30 era a de que órgãos públicos vinculados ao governo federal estivessem presentes nas regiões mais distantes, em geral controladas por oligarquias locais e regionais. Assim, embora as diretrizes do Sesp fossem descentralizadas, elas não destoavam da política do Estado brasileiro, uma vez que sua prática era de, igualmente, levar profissionais da saúde para o interior do país, marcando a presença do poder público.

O Sesp, portanto, esteve afinado com os interesses do Estado brasileiro. Além disso, DNS e Sesp seguiam orientações debatidas em fóruns internacionais. Assim, insiste o autor, na década de 1930 a administração da saúde pública no Brasil conheceu experiências diversas, combinando várias tradições, sem que elas necessariamente fossem excludentes. Os interesses norte-americanos não entravam em contradição com a política getulista de expandir a autoridade do Estado sobre território brasileiro.

A guerra acabou em 1945, mas o Sesp, embora planejado para atuar apenas durante o conflito mundial, continuou existindo - os acordos 
assinados em 1943 se estenderiam até 1948. Inicialmente um órgão de existência temporária e vinculada aos interesses norte-americanos na guerra, o Sesp manteve-se graças a outros interesses. A partir de fins da década de 1940 o Sesp esteve orientado por duas diretrizes: a primeira, a política desenvolvimentista; a segunda, as políticas internacionais de saúde que, atreladas aos conflitos da Guerra Fria, necessitavam demonstrar a superioridade dos países capitalistas nessa área. Desenvolvimentismo e Guerra Fria asseguraram sobrevida ao Sesp, pelo menos até fins da década de 1980.

A instituição, desse modo, participou ativamente do clima de euforia do pós-guerra no campo da saúde. Afinal a invenção da penicilina e do DDT, para citar alguns produtos, permitiu a construção de imagens e representações que aludiam à erradicação das doenças que debilitavam os trabalhadores dos países pobres. Com a eclosão da Guerra Fria em 1947, o Iaia, cujos programas de saúde e saneamento eram apontados como modelos, manteve os acordos bilaterais com o Sesp.

Poucos anos depois, no entanto, o Iaia foi extinto nos Estados Unidos. Sem sua vinculação internacional, o Sesp, para manter suas características, foi transformado em fundação em abril de 1960. As pressões sociais, no Brasil, para o prosseguimento de suas ações foram muito fortes, sobretudo na região Amazônica, onde o Sesp tivera atuação muito positiva entre a população mais pobre. Mas com a mudança de estatuto e sua subordinação ao Ministério da Saúde, a instituição perdeu em autonomia e gestão de recursos, sem contar as ingerências político-partidárias em sua diretoria. Em 1990 o órgão foi extinto e seus quadros, aproveitados pela Superintendência de Campanhas, que foi integrada à Fundação Nacional de Saúde (Funasa). Era o final de uma importante experiência de saúde pública no Brasil.

A História do Brasil republicano, nos últimos anos, vem conhecendo um enorme esforço de reciclagem e renovação em suas referências teóricas e seus métodos. Ao recorrer a abordagens sofisticadas, algumas delas ainda recentes no Brasil - a exemplo da história das políticas de saúde pública -, os historiadores da República têm alcançado excelentes resultados em suas pesquisas. Nesse caso, sem dúvida, inclui-se Políticas internacionais de saúde na era Vargas. O estudo de André Luiz Vieira de Campos sobre a trajetória do Serviço Especial de Saúde Pública é importante contribuição para a historiografia sobre a história da saúde e para os estudos republicanos no Brasil. 